\title{
Investigating the impact of electronic health record on healthcare professionals
}

\author{
Amira Mohammed ${ }^{a}$, Ahmed Mehrez ${ }^{b^{*}}$ and Lamia Aladel ${ }^{b}$
}

${ }^{a}$ Hamad General Hospital, Qatar

${ }^{b}$ Sadat academy for Management Sciences, Egypt

C H R O N I C L E

\begin{tabular}{l}
\hline Article history: \\
Received: September 9, 2020 \\
Received in revised format: Sep- \\
tember 9, 2020 \\
Accepted: November 3, 2020 \\
Available online: November 3, \\
2020 \\
\hline Keywords: \\
Electronic health record (EHR) \\
Healthcare professionals \\
Private hospitals \\
Qatar
\end{tabular}

\section{Introduction}

Information technology (IT) has turned to be a significant part of many organizations to improve the quality of work (Shahmoradi, Darrudi, Arji, \& Nejad, 2017). By using modern IT, healthcare can promote a higher quality of care (U.S. Department of Health \& Human Services [DHHS], 2009). For many organizations, investment in information technology has become a way of communication, improving quality, performing tasks, increasing profit, and improving safety. Hence, healthcare use digitalization in the form of Electronic Health Record (EHR) (Steinhubl, \& Topol, 2015). EHR mainly used to manage patients' health information (Singh \& Muthuswamy, 2013). Electronic health record (EHR) is seen as a positive, and it impact its use and increasing all over the world (Celikkan, Sahin, \& Senuzun, 2013). EHR allows the share of data in each region (Ngafeeson, 2015). EHR is considered as a road map, which enhances the efficiency of hospitals' work (Holanda et al., 2012). EHR can connect and communicate information between healthcare professionals in remote areas (Houser \& Johnson, 2008). Usually, when any new system appears and becomes available over the counter for organizations and populations use, it may face some level of resistance from many users, especially senior people who have adapted to use a manual review system for ages. This level of resistant may decline gradually with time and become converted from a resistant system to a friendly user system. Many studies have analyzed the influence of using information technology in many sectors, such as in business or healthcare facilities. Many studies aimed to assess the positive and negative influence of the EHR. It has been arguing that EHR can change the core organization, which in turn can improve the working process (Deokar, \& Sarnikar, 2016).

* Corresponding author.

E-mail address: ahmed.mehrez@sadatacademy.edu.eg (A. Mehrez)

(C) 2021 by the authors; licensee Growing Science, Canada. doi: $10.5267 /$ j.ijdns.2020.11.001 
In this paper, an examination and review will be addressed about the influence of using the EHR system from the perspective of healthcare professionals. EHR system is considered as an essential component of information technology used in this era (Petrides et al., 2017). The electronic health record is an advanced software system, which is a breakthrough brought to the field of hospitals (Petrides et al., 2017). This revolutionary system affects healthcare providers as end-users and allows improving online services. It includes entering data and information by healthcare professionals, such as physicians, nurses, pharmacists, dietitians, and many other healthcare professionals. The EHR system is expected to improve performance and deliver a high quality of care (Petrides et al., 2017). The advantages of using the EHR will lead to long-term acceptance by healthcare providers inevitable (Hawley, Hepworth, Jackson, \& Wilkinson, 2017). As a result, the number of hospitals using the EHR system is increasing in many countries. The advantages of using the EHR outweigh the disadvantages. These advantages include more flexibility to access information, save time, and to share information among healthcare professionals.

There have been few studies, which represent the post-implementation influence on healthcare professionals. In Qatar, there are not enough studies, which describe the post-implementation influence of EHR on healthcare settings. Hence, this study is conducted to analyze the influence of the EHR on healthcare professionals in three healthcare settings in Qatar, Al-Ahli Hospital, Al-Emadi Hospital, and Doha Clinic Hospital in Qatar.

\section{Research Objectives:}

1. To assess the influence of the EHR on healthcare professionals in Qatar.

2. To examine the impact of the EHR in improving efficiency and quality of work in hospitals after implementing the system in Qatar.

3. To develop in the research, a conceptual model on the influence of the EHR system on healthcare professionals in Qatar.

Research question is:

How do healthcare professionals in healthcare settings in Qatar perceive the use of EHR system?

\section{Literature Review}

EHR system dated back 1967 at the University of Vermont in which the paper records converted in to electronic record systems (Mehmood et al., 2017). Then in 1970, the system moved and utilized in the Medical Centre Hospital of Vermont (Mehmood et al., 2017). The EHR system connects health information and exchanges this information among hospitals and healthcare professionals. This facilitated the central role of communicating the massive amount of data (Cyganek et al., 2016). Different factors impact the use of the system in which some of these factors are the level of acceptance by healthcare professionals of this software application and how they perceive using the EHR system (Vitari \& Ologeanu-Taddei, 2018). Most developed and developing countries shifted to use the EHR system to improve efficiency in healthcare settings (Alasmary, El Metwally, \& Househ, 2014).

\subsection{Dietitians and EHR}

Generally, the studies about dietitians who use EHR are very limited (Lövestam, Orrevall, Koochek, Karlström, \& Andersson, 2015). Even though the term nutrition informatics first used in 1996 (Ayres \& Hoggle, 2012). EHR has increases the referrals rate, especially for patients who have chronic diseases (Probst, 2011). Moreover, dietitians may require writing a diet plan for patients to explain the details of the plan (Hawley et al., 2017). Therefore, they require double time-consuming to document their work at hospitals (Hawley et al., 2017). Consequently, they have a different point of view while dealing with and using the system (Vitari \& Ologeanu-Taddei, 2018).

Dietitians in Australia and in the USA the EHR in terms of time reported comfortable EHR use in terms of data management and analyze. Australians had higher training and reported an effective ability to improve patients care with higher efficiency (Maunder et al., 2015). Moreover, another study found EHR provides the calculated body mass index, and the routine documented the height and weight screening and follow-up (Ayres \& Hoggle, 2012). Overall, it has been found that the dietitians' documentation in Swedish needs improvement regarding evaluation indicators, and in the process of setting goals (Lövestam et al., 2015).

\subsection{Physicians and Electronic Health Record}

While many healthcare providers utilize the EHR system, physicians play a significant role in the process of progressing this system. Physicians' documentations reviewed more frequently than other healthcare professionals (Penoyer et al., 2014). Many physicians considered EHR as an end of the problem of multiple testing of a blood test, which is available in one region and can be accessed and reviewed by many hospitals and health centers without the need to repeat the test (O'SULLIVAN, Billing, \& Stokes, 2011). This has been supported in another study as they found $80 \%$ of physicians consider using the EHR system as systematic storage of patients' information (Chao, Hu, Ung, \& Cai, 2013). This has supported by Shachak and Reis (2009), as they found in their study the positive influence of using the EHR system in terms of exchanging and clarifying 
medical information. The same study found many patients do not know exactly the name of the medications they were taking; hence, the EHR system helped physicians to identify the medication names (Shachak \& Reis, 2009).

In accordance, Shield et al. (2010) explained in their study how physicians could pull patients' information immediately. Nevertheless, Alharthi, Youssef, Radwan, Al-Muallim, and Zainab (2014), reported in their study that $61 \%$ of physicians (out of 115 physicians) hope to abandon the use of the EHR system and go back to the use of the paper record. In another domain, Ventres et al. (2006) found out that physicians consider the use of the EHR system as a third party and facilitator between them and their patients because they behave and share the documented shared work of many healthcare professionals.

Physicians' ability to work with efficiency and quickly has increased after the EHR system has implemented (Castillo et al., 2019). Also, the EHR system alert physicians and other healthcare professionals to drug contraindications or interactions, as well as save space in their offices (O'SULLIVAN et al., 2011). The system of computer-based alert resulted in better outcomes among hospitals (Rind et al., 1994). Physicians order mostly orders in the EHR system, and they more likely able to identify and report clinical changes in patients' conditions (Sakata et al., 2016).

According to Cyganek et al., (2016), physicians" notes considered complex data that are huge and fast-growing in terms of volume. While El Mahalli (2015) explained there was no use of patients' communication tools by physicians; for instance, no emails were sent to patients from the EHR system. This may indicate some level of ineffective utilization of some services that are available in the system (El Mahalli, 2015). This was supported by Mehmood et al. (2017) who recommend in their study the need for proper training to physicians to ensure that they are capable of managing, utilizing, and operating the EHR system (Mehmood et al., 2017).

In a study conducted by Jabali (2017), the author stated that the adoption of the EHR system among young physicians was highly significant. This significance was evident, especially for those who work in large hospitals or live in the Western United States (Jabali, 2017). Also, the author stated that most people prefer to use direct communication with their physicians, mainly when things affect their health (Jabali, 2017). Therefore, email communication may be useless because patients require to see their physicians for further explanation about their health condition (Jabali, 2017). Moreover, as per a study conducted by Dowding et al. (2015), effective communication with other healthcare professionals was noted by physicians after they started using the EHR system (Dowding et al., 2015).

The system contains educational materials, which benefit resident teams, and improve group problem-solving and discussion (Mosher, Lose, Leslie, Pennathur, \& Kaboli, 2015). Moreover, they explained the availability of educational materials as a measure of success (Mosher et al., 2015). In a study conducted by Vitari and Ologeanu-Taddei (2018), they found that among physicians, the percentage of missing documented data is less than $7.5 \%$. Also, according to Kruse, Hays, Orav, Palan, and Sequist (2017), the EHR system has improved most quality of care delivered by physicians, and it led the function of the system to guide the work to a positive way.

Moreover, the inadequate use of the new information technology by physicians have been supported by Vitari and OlogeanuTaddei (2018), who explained the unwillingness of physicians to change some of their traditional clinical practice at hospitals. Also, they explained that physicians might consider and perceive the new use of the EHR system as a lead of losing their power on their jobs by challenging them to practice new technology fields (Vitari \& Ologeanu-Taddei, 2018). Furthermore, El Mahalli (2015) explained that the review of progress notes shows the lowest utilization.

\subsection{Pharmacists and EHR}

Generally, the EHR system supported pharmacists to maintain accurate patients' medication lists (Andrus, 2012). Health information technology provided a chance for pharmacists to become involved indispensable members in patients' care (Anderegg \& Gumpper, 2012). EHR system supported pharmacists to have better productivity measures and enhanced medication safety by reducing prescribing errors to avoid harming patients (Horning, 2011). In the beginning, pharmacists were resistant to change, but they realize there is no way to avoid using or implementing the system instead, they started to learn other ways in the system (Chalmers, Siska, Le, \& Knoer, 2018).

Horning (2011) found that most pharmacists reported comfortable and confident of using the EHR system after six months of initiating implementing the system, especially pharmacists stop entering the physicians order manually from hand-writing prescriptions. From the perspective of pharmacologists, there is an improvement in the process of recording the adverse events of medications, which supported them to improve their recording habits (de Hoon, Hek, van Dijk, \& Verheij, 2017). The percentage of clarification, incorrect doses from pharmacists after implementing the EHR system was lower (Singer \& Fernandez, 2015).

In a study conducted by Pedersen, Schneider, and Scheckelhoff (2016), after implementing the EHR system, the percentage of reviewed ordered medications increased before patients take their medications. Thus, there was a dramatic decline in the rate of unreviewed medications order (Pedersen et al., 2016). Also, the availability to analyze data and design progress note format was higher after implementing an EHR system, quicker access to patients' information, and improved the quality of care (Jawhari, Ludwick, Keenan, Zakus, \& Hayward, 2016). And it opens the door for evaluating the performance at hospitals and accurate statistical reporting (O'SULLIVAN et al., 2011). 
Moreover, pharmacists supported the use of the system as a factor of reducing medical errors, which enhance a required patients' safety and deliver high quality of care (Shahmoradi et al., 2017). Also, Akhu-Zaheya et al. (2018), describe the use of the EHR as a better system than the paper used in term of quality, quantity, and structure. Furthermore, Hawley et al. (2017), supported the use of the system as it improves and enhances the higher level of coordination and integration among healthcare professionals. Johnson and Brownlee (2018) explained in their study that EHR allows providing comprehensive pharmacists services to their patients.

Nonetheless, Andrus (2012) found that pharmacists reported as disadvantages of the EHR system it does not discontinue the completed course medications, nor capture over-the-counter medications, which means the medication list is not updated. Thus, the medications list accuracy is not continually verified, which is directly affecting the medication reconciliation practice in hospitals. Moreover, according to Horning (2011), pharmacists supported reducing the overload medication errors, which may be caused by the EHR system by stopping allowing more than one patient's information at a time on the computer screen by healthcare professionals.

\subsection{Nurses and Electronic Health Record}

Nurses are considered the most significant end users of the EHR system; therefore, understanding their influence and point of view about the system is significant (Strudwick \& McGillis Hall, 2015). Many nurses perceive the use of the EHR system as a positive step in their clinical areas, which continuously improves day to day efficiency, safety, and communication as they get adapted to a comprehensive system (Dowding et al., 2015). According to Carayon (2011), overtime intensive care unit nurses accepted, and understood well the EHR system in-depth after 12 months of implementation as compared to three months.

In terms of time management, Likourezos et al. (2004) found in their study, nurses believed after they started using the EHR system, they were able to complete their work faster. Nurses find the system released them from some problems, which they were facing before implementing an EHR system, such as missing patients' files, difficult hand-writing of some physicians, and incorrect interpretation, which may lead to give wrong medications (O'Mahony, Wright, Yogeswaran, \& Govere, 2014).

Moreover, they described the system as more time-efficient regarding the daily charting work, and for looking exactly and directly to specifically wanted information (Bardach, Real, \& Bardach, 2017). Furthermore, according to Dowding et al. (2015) EHR system can link some types of data between flow sheets, which could reduce the amount of documented data by nurses as the system is capturing automatically repeated recorded data (Dowding et al., 2015). Moreover, Schenk et al. (2018) explain that some nurses significantly spent more time with patients after implementing the EHR system. On the other hand, some nurses who use the EHR system reported that they have limited time to spend with patients after they started using the system (Dowding et al., 2015).

According to Strudwick and McGillis Hall (2015), they explained in their study in some hospitals, before starting implementing the system, many nurses expected and felt EHR system would be a very complicated system, which may be overshadowed. While Akhu-Zaheya, Al-Maaitah, and Hani (2018), describe nurses' documentation as a crucial role in most hospitals departments, which still have an inadequate level of quality and lack of nurses' skills and knowledge to use the system in both electronic and paper-based work (Akhu-Zaheya et al., 2018).

Moreover, administrators and policymakers need to identify the importance of improving nursing documentation and bring it to the highest level and standard to deliver the best quality care (Akhu-Zaheya et al., 2018). This has been supported by Strudwick and McGillis Hall (2015), who suggested and recommend the availability of helpdesk team who are present to help nurses and allow them to contact if they have problems and face difficulties in progressing their electronic health record. Also, this may participate in increasing the level of nurses' acceptance of the EHR system (Strudwick \& McGillis Hall, 2015). Hence, Dowding et al. (2015) have highlighted the significance of providing additional training and explanation of the EHR system to nurses who struggle with the demand of the system.

Nonetheless, Kossman and Scheidenhelm (2008) proclaimed that nurses described the downtime of computers cause a delay in charting. Also, they found the downtimes of the EHR system very frustrating, especially when they need to know the medications due to be given for their patients (Kossman \& Scheidenhelm, 2008). Moreover, some of the nurses found an insufficient number of functional computers, which interferes with their ability to manage their work and time-efficiently (Kossman \& Scheidenhelm, 2008).

\subsection{Advantages and disadvantages of using the EHR system}

Generally, the EHR system is considered one of the most critical information technology achievements in the healthcare domain in terms of efficiency (Shahmoradi et al., 2017). Healthcare professionals described the EHR system used as the most common way to gain overall conditions and insights about patients (Penoyer et al., 2014). The system sends alert to healthcare professionals regarding any drug reaction (Emmendorfer, 2012).

There was a study of SWOT (Strength, weakness, opportunities, and threats) analysis effect in the process of implementing the EHR system (Shahmoradi et al., 2017). The result of this study was as follow: The strength of using this system is the 
quick analysis access to information while the weakness is the lack of infrastructure and hardware. The opportunities are the availability of health statistics and shared information among healthcare sectors, which can be presented as indicators and benchmarks. And the threats are a lack of strategic planning between physicians and other healthcare professionals (Shahmoradi et al., 2017).

The advantages of using the EHR system is to manage the enormous amount of data, which continuously keeps increasing and needs to be collected and maintained in one system, which is significant in improving communication (Akhu-Zaheya et al., 2018). This has been supported by Hawley et al. (2017), who describe paper-based documentation as a bulk and inconvenient way of work at hospitals, especially if it gets lost or mixed with other documents. Moreover, many healthcare professionals reported that having one system containing all patients' information is much better than waiting for each patient's file, especially in the rush hours (O'SULLIVAN et al., 2011).

The analysis process of the EHR system is complex and characterized by five Vs. (Cyganek et al., 2016). The five Vs. are volume, variety, veracity, velocity, and value. The fifth $\mathrm{V}$ is called value because it makes sense when there is a quality benefit of data, healthcare improvement, and hospitals get higher quality as a result of analyzing their data (Cyganek et al., 2016). This is characterized as the most complex data that can be obtained by organizations (Cyganek et al., 2016).

According to Shahmoradi et al. (2017), the EHR system is considered enormous advantages and achievement in the field of information technology as a determinant of delivering high quality of work. Also, they described the use of the EHR system as a comprehensive device of patients' condition, which includes all required clinical data that need to be accessed and communicated by healthcare professionals (Shahmoradi et al., 2017).

On the other hand, Schenk et al. (2018) describe using the EHR system as a disadvantage when they compared hospitals use and do not use the system, and they found that EHR system has no significant impact on time the length of time spent for documentation (Schenk et al., 2018). And physicians do not look to patients and look only to computer screens (Makam et al., 2014). Cole, Pflugeisen, Schwartz, and Miller (2018), stated that the use of the EHR systems supported identifying the degree of insufficient data that has been recorded by healthcare professionals. This helps them in doing analysis reports; for instance, they found many healthcare professionals document tobacco uses by yes or no without asking patients about the frequency, type, and for how long patients have been smoking. Moreover, in a study by Hawley et al. (2017), they found the inadequate level of awareness in using the EHR system lead to have many barriers. Then it leads to having inefficient use of the available service efficiently (Hawley et al., 2017). Other disadvantages of the system are the loss of eye contact, and faceto-face communication between healthcare professionals and their patients as reported more focus observed on computers screens, which needs to be modified by improving communication technique (O'SULLIVAN et al., 2011; Taylor, Ledford, Palmer, \& Abel, 2014). And note not all notes read by other healthcare professionals (Bardach, Real, \& Bardach, 2017).

\section{Methodology}

\subsection{Study Design}

This study is descriptive, cross-sectional, and has been conducted to assess the influence of using the EHR system on healthcare professionals in Qatar. A validated and reliability of the survey were selected from the study of Al-Harbi (2011). Then the quantitative survey distributed by emails to all physicians, pharmacists, nurses, and dietitians who work in the three selected hospitals in Qatar. The sample was convenient.

\subsubsection{Hypothesis}

$\mathrm{H}_{1}$ : There is a significant difference between the perception of employees with good training in IT and employees with inadequate or no training in IT toward the benefits of electronic health records in healthcare settings.

\subsubsection{Survey Instrument}

The quantitative research method by distributing a survey was used. The questioner cited from another study (Al-Harbi, 2011), and selected then distributed by emails to the four selected job titles in the three hospitals in Qatar. The selection of the survey was based on the research objectives of this study. The survey includes demographic data of participants, statements about perceptions of health information, and 25 statements in benefits, barriers, and motivation of using electronic health records. The 25 statements using a five-point Likert-scale, which are 1=Strongly Disagree, 2=Disagree, $3=$ Neither agree nor disagree, 4=Agree, and $5=$ Strongly agree. The questioner was validated by two faculty members from two different hospitals.

Cronbach's alpha for benefits, barriers, and motivations values were 0.955 for benefits, 0.871 for the barriers, 0.862 for the motivations, in which all the three dimensions were strictly above 0.7 , which is considered acceptable. Hence, all three dimensions were consistent.

\subsubsection{Participants}

The population of this study is from four job titles, which are physicians, pharmacists, nurses, and dietitians. The population size in the selected three hospitals is 1289 . Out of 1289 , the sample size was 210 participants using convenience sampling, 
which is a non-probability sampling technique. The survey was distributed during October and November 2019. The survey was a link survey sent to the selected job titles through the supervisors, coordinators, and secretaries in the three hospitals. The given optional response rate was $16.3 \%$.

\subsubsection{Analysis}

After the data was collected and extracted, Statistical Package for Social Sciences (SPSS) used to do the analysis. The analysis includes the frequency table, descriptive statistics, reliability statistics, correlation, and rotated computed matrix of the participants' data (healthcare professionals), perception of participants' benefits, barriers, and motivation of using the EHR system. Also, one of the analyses was ANOVA one-way to test whether benefit and knowledge were with a good level of IT training or inadequate IT training.

\subsubsection{Ethical Consideration}

This study was approved by the institutional review board (IRB) of Qatar University with research ethics approval number QU-IRB 1132-E/19. And as well as a written approval from the three selected hospitals' administrations in Qatar with the consent of participants. The hospitals' approval was obtained from the medical directors. Participants' names were kept anonymous.

\section{Results}

By using SPSS, the results of this study represented in tables and explanations the analyzed collected data by the distributed survey. The analysis includes the frequencies of the demographic data, the descriptive statistics, the reliability, the correlations, the rotated component matrix, and the ANOVA one-way test.

\subsection{Frequency figures}

Fig. 1 describes the analysis of the demographic data, the knowledge, and the frequency of IT use by the participants. Most participants were female, $68.6 \%$ (144), while only $31.4 \%$ (66) were male. The age classification was as follows: $10.5 \%(22)$ falls between $22-29$ years, $44.3 \%$ (93) between $30-39$ years, while $23.3 \%$ (49) between $40-49$ years old, and the remaining 50 years and above were $21.9 \%$ (46).

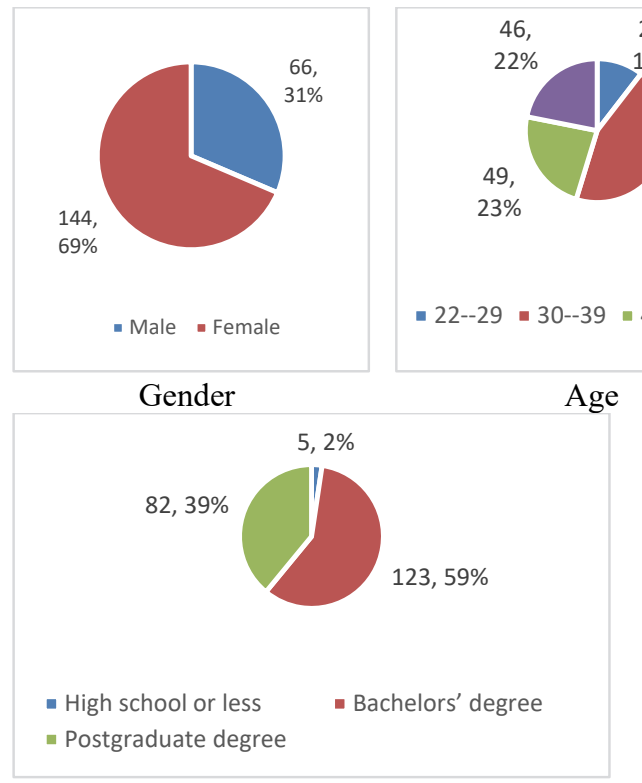

Education

Age
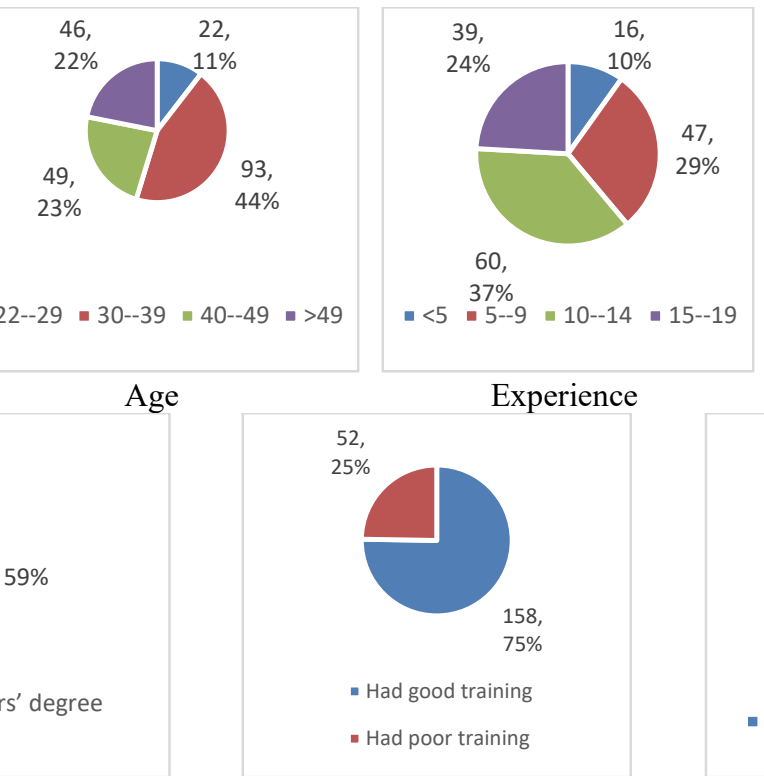

Knowledge of IT Applications

Training

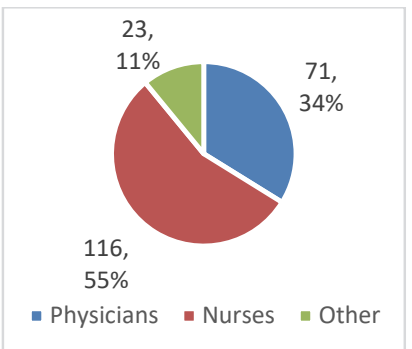

Fig. 1. Frequency of data

In terms of educational level, most participants were holding bachelor's degrees $58.6 \%$ (123), followed by $39 \%$ ( 82 ) for a postgraduate degree, while the remaining $2.4 \%$ (5) were high school or less. The years of work experience for the participants ranged from less than five years to more than twenty years. About 28.6\% (60) were between ten to fourteen years of work experience, followed by $22.9 \%$ (48) who had twenty years and above, $22.4 \%$ (47) who had five to nine years, $18.6 \%$ (39) who had fifteen to nineteen years, and lastly $7.6 \%$ (16) of participants had less than five years of experience. Moreover, the table shows the job titles of the participants as follows $55.2 \%$ were nurses, followed by 33.8 (71) were physicians, and the remaining $11 \%$ (23) were either pharmacists or dietitians. The IT application's knowledge level in the table was $75.2 \%(158)$ of the 
participants had good training, while the remaining 24.8\% (52) selected that they had poor IT training. With regards to frequency use of IT, $80 \%$ (168) of participants reported always use IT, followed by $18.6 \%$ (39) selected sometimes use IT, and lastly $1.4 \%$ (3) reported rarely used IT.

\subsection{Descriptive Statistics}

The following tables will be described in terms of mean and standard deviation (to measure the spread of data); hence the Table 1 explains the categories of the mean

Table 1

Scale and Criteria of Mean

\begin{tabular}{ll}
\hline Mean & The Criteria \\
\hline $1.00-2.33$ & Indicate low agreement with a statement \\
$2.33-3.66$ & Indicate moderate agreement with a statement \\
$3.66-5.00$ & Indicate high agreement with a statement \\
\hline
\end{tabular}

The table below shows the descriptive statistic of the benefits section in the survey, which includes 13 items. The mean shows that the highest mean value is the benefit for BF2 (easier to find investigation results) as the mean was 4.36. Hence, most of the participants have high agreement on that statement. There were no low agreements in all mean results of benefits statements. Out of the 13 items in the benefit, there was only one statement BF13 with a moderate agreement, which was the lowest mean 3.63. The highest mean followed by 4.23 for both BF1 and BF4. The standard deviation was very close to 1.0 for all the items, which indicate low variation, better and more stable results, except for the result of BF13 (decreases workload), which was 1.184. The lowest standard deviation was 0.907 for BF12 (improves quality of patients' care). This has the following lowest SD .9939.

Table 2

Descriptive Statistics-1

\begin{tabular}{|c|c|c|c|c|c|}
\hline & $\mathrm{N}$ & Minimum & Maximum & Mean & Std. Deviation \\
\hline$\overline{\mathrm{BF} 1}$ & 210 & 1 & 5 & 4.23 & 1.024 \\
\hline BF2 & 210 & 1 & 5 & 4.36 & .939 \\
\hline BF3 & 210 & 1 & 5 & 4.00 & 1.033 \\
\hline BF4 & 210 & 1 & 5 & 4.23 & .957 \\
\hline BF5 & 210 & 1 & 5 & 4.11 & .947 \\
\hline BF6 & 210 & 1 & 5 & 4.00 & 1.051 \\
\hline BF7 & 210 & 1 & 5 & 4.20 & 1.053 \\
\hline BF8 & 210 & 1 & 5 & 4.16 & .983 \\
\hline BF9 & 210 & 1 & 5 & 3.97 & .990 \\
\hline BF10 & 210 & 1 & 5 & 3.80 & 1.063 \\
\hline BF11 & 210 & 1 & 5 & 3.79 & .945 \\
\hline BF12 & 210 & 1 & 5 & 3.98 & .907 \\
\hline BF13 & 210 & 1 & 5 & 3.63 & 1.184 \\
\hline $\begin{array}{l}\text { Valid N } \\
\text { (listwise) }\end{array}$ & 210 & & & & \\
\hline
\end{tabular}

Table 3

Descriptive Statistics-2

\begin{tabular}{|c|c|c|c|c|c|}
\hline & $\mathrm{N}$ & Minimum & Maximum & Mean & Std. Deviation \\
\hline$\overline{\mathrm{B} 1}$ & 210 & 1 & 5 & 3.44 & 1.149 \\
\hline B2 & 210 & 1 & 5 & 3.61 & 1.186 \\
\hline B3 & 210 & 1 & 5 & 3.76 & 1.027 \\
\hline B4 & 210 & 1 & 5 & 3.72 & 1.044 \\
\hline B5 & 210 & 1 & 5 & 3.47 & 1.081 \\
\hline B6 & 210 & 1 & 5 & 3.41 & 1.130 \\
\hline B7 & 210 & 1 & 5 & 3.43 & 1.001 \\
\hline B8 & 210 & 1 & 5 & 3.21 & 1.118 \\
\hline
\end{tabular}

Table 3 shows the eight statements of barriers. The highest mean was 3.76 in B3 (System being down frequently), which is considered high agreement. Most of the statement was in the moderate agreement category, and there was no low agreement. The Standard deviation (SD) of 1.001 is the lowest SD, which is the best lower result in this table. Followed by 1.027 , which is the second-lowest, and it shows that it's almost equal to 1 .

Table 4

Descriptive Statistics-3

\begin{tabular}{|c|c|c|c|c|c|}
\hline & $\mathrm{N}$ & Minimum & Maximum & Mean & Std. Deviation \\
\hline M1 & 210 & 1 & 5 & 3.90 & .806 \\
\hline M2 & 210 & 1 & 5 & 4.03 & .891 \\
\hline M3 & 210 & 1 & 5 & 3.87 & .825 \\
\hline M4 & 210 & 1 & 5 & 4.04 & .794 \\
\hline $\begin{array}{l}\text { Valid N } \\
\text { (listwise) }\end{array}$ & 210 & & & & \\
\hline
\end{tabular}


In addition, Table 4 shows the four statements of motivation. All the mean results in the table fall in high category agreement for all the motivation statements by participants. There were no moderate nor low agreement results in the table. The SD in the table shows that all the four results were low in their value, which means they are more consensus on the participants' agreement.

Table 5

Descriptive statisctics-4

\begin{tabular}{|c|c|c|c|c|c|}
\hline & $\mathrm{N}$ & Minimum & Maximum & Mean & Std. Deviation \\
\hline Benefits Mean & 210 & 1.00 & 5.00 & 4.0352 & .81272 \\
\hline Barriers Mean & 210 & 1.00 & 5.00 & 3.5065 & .79286 \\
\hline Motives Mean & 210 & 1.00 & 5.00 & 3.9571 & .69770 \\
\hline $\begin{array}{l}\text { Valid N } \\
\text { (listwise) }\end{array}$ & 210 & & & & \\
\hline
\end{tabular}

Table 5 shows all the means of the three dimensions of the 25 statements, which are for BF, B, and M. The highest mean agreement was for benefits mean. The standard deviation for all the three dimensions was in low values, which reflects that the agreement is consensus.

\subsection{Reliability Statistics}

To measure the reliability of this study, reliability measured for the three dimensions (BF, $\mathrm{B}$, and $\mathrm{M})$. Hence, the table below shows the measuring of the internal consistency without bias of the analyzed variables, questionnaire scale by using Cronbach's Alpha. The results of the three variables, which are benefits (13 items), barriers (8 items), and motives (4 items), were strictly more than 0.7 , which is considered acceptable. And were as follows: The BF reported 0.955 (excellent), while the B reported 0.871 (Very Good), and $\mathrm{M}$ was 0.862 (Very Good). Hence, all the reliability dimensions were consistent.

Table 6

Cronbach's Alpha

\begin{tabular}{lll}
\hline All Variables & Number of Items & Cronbach's Alpha \\
\hline Benefits (BF) & 13 & 0.955 \\
Barriers (B) & 8 & 0.871 \\
Motives (M) & 4 & 0.862 \\
\hline
\end{tabular}

\subsection{Correlations}

To measure the linear relationship and degree to which the three determinants are related, correlation analysis used. Table 7 shows that Pearson Correlation for benefits means, barriers mean, motives were significant at the level of 0.01 . At the level of 0.01 , the strongest correlation was between benefits mean, and motives mean. Followed by .0422 between motives mean and barriers mean. At the level of 0.05 , there was a correlation at 0.170 between benefits mean, and barriers mean.

Table 7

Correlations

\begin{tabular}{llccc}
\hline & & Benefits Mean & Barriers Mean & Motives Mean \\
\hline Benefits Mean & Pearson Correlation & 1 & $.170^{*}$ & $.461^{* *}$ \\
& Sig. (2-tailed) & & .014 & .000 \\
& $\mathrm{~N}$ & 210 & 210 & 210 \\
\hline Barriers Mean & Pearson Correlation & $.170^{*}$ & 1 & $.422^{* *}$ \\
& Sig. (2-tailed) & .014 & .000 & 210 \\
& $\mathrm{~N}$ & 210 & 210 & 1 \\
\hline Motives Mean & Pearson Correlation & $.461^{* *}$ & $.422^{* *}$ & .000 \\
& Sig. (2-tailed) & .000 & 210 & 210 \\
& $\mathrm{~N}$ & 210 & & 210 \\
\hline
\end{tabular}

*. Correlation is significant at the 0.05 level (2-tailed).

**. Correlation is significant at the 0.01 level (2-tailed).

\subsection{Rotated Component Matrix}

In the table below, the rotated component matrix contains the estimated correlation between every variable and the components. It helps to determine and identify what are the things that represented by the components. Hence, the table below three factors used to determine and construct validity. Factor one contains 13 items of benefits. Factor two contains the results of seven items, and factor 3 includes four items. 
Table 8

Rotated component matrix

\begin{tabular}{|c|c|c|c|}
\hline & \multicolumn{3}{|c|}{ Components } \\
\hline & 1 & 2 & 3 \\
\hline$\overline{\text { BF } 1}$ & 0.790 & & \\
\hline BF 2 & 0.858 & & \\
\hline BF 3 & 0.775 & & \\
\hline BF 4 & 0.836 & & \\
\hline BF 5 & 0.884 & & \\
\hline BF 6 & 0.846 & & \\
\hline BF 7 & 0.818 & & \\
\hline BF 8 & 0.844 & & \\
\hline BF 9 & 0.828 & & \\
\hline BF 10 & 0.660 & & \\
\hline BF 11 & 0.742 & & \\
\hline BF 12 & 0.728 & & \\
\hline BF 13 & 0.710 & & \\
\hline B 1 & & 0.665 & \\
\hline B 2 & & 0.663 & \\
\hline B 3 & & 0.730 & \\
\hline B 4 & & 0.718 & \\
\hline B 5 & & 0.758 & \\
\hline B 6 & & 0.850 & \\
\hline B 7 & & 0.780 & \\
\hline B 8 & & 0.827 & \\
\hline M 1 & & & 0.758 \\
\hline M2 & & & 0.755 \\
\hline M 3 & & & 0.754 \\
\hline M 4 & & & 0.802 \\
\hline
\end{tabular}

ANOVA One-way test was performed to identify whether there are significant differences between the means of the benefits items between participants who had good training and those who had poor training based on the knowledge level of response.

The obtained result of .043 in table 10 shows that there is a statistically significant difference between the knowledge levels of good IT training and no IT training in benefit variables. Hence, we accept the hypothesis

Table 9

Anova one-way

\begin{tabular}{lccccc}
\hline & Sum of Squares & df & Mean Square & F & Sig. \\
\hline Between Groups & 2.706 & 1 & 2.706 & 4.159 & .043 \\
Within Groups & 135.342 & 208 & .651 & & \\
\hline Total & 138.048 & 209 & & \\
\hline
\end{tabular}

\section{Discussion and conclusion}

The result of the statistical analysis revealed that the majority $(80 \%)$ of the participants always use the EHR system when the survey was distributed and that there was $18.6 \%$ sometimes use the system. This has been supported and consistent with that of Makam et al. (2014) as they reported in their study that $94 \%$ timely access to the EHR system by healthcare professionals.

Moreover, the result of the conducted study provides information about our accepted hypothesis of those healthcare professionals who had good training in IT use, which was $(75.2 \%)$ were more than those who had inadequate training in IT use $(24.8 \%)$. This result has been supported by Culler, Jose, Kohler, and Rask (2011), who have found the quality of IT training was adequate and excellent. Also, most of the mean results were in the category of high agreement, while the remaining were moderate agreement, and there were no low agreement statements among means. Hence, healthcare professionals perceive the use of the EHR beneficial to their work after it has been implemented. As regards the influence of attending IT training, healthcare professionals who had good training in IT reported getting more benefits in using the EHR system after the EHR system implemented in hospitals than those who had inadequate IT training. Similarly, this result is consistent with the findings of Al-Harbi (2011), who acknowledge her study of the positive impact of IT good training and adoption on healthcare professionals. To answer the research question of this study, the result of table three shows that high mean scores were for the twelve statements in the benefits (BF), except for the BF13 (Decreases workload), which had a moderate agreement. Hence, the means of the BF ranged from 3.63 to 4.36. This result revealed that healthcare professionals perceive the use of EHR as a valuable system.

\subsection{Limitations and future work}

There were a few limitations in this research study that limited the ability of the researchers to go further in-depth. One of the limitations was the process of distributing the survey was limited to private hospitals in Qatar, as the administrations" approval took a shorter period than public or governmental healthcare settings. The other limitation was the need to include more healthcare professional in future studies such as laboratory staff, and administrative staff such as clerks who use the 
EHR system. Another limitation was the sample size, and it was a small size due to the limited responses from some of the healthcare professionals who are busy and could not answer the online link survey.

Future studies may be conducted in governmental healthcare settings in Qatar and include more than 500 participants. Moreover, more time may need to be given in the process of distributing the online survey, such as three to four months. Also, including a qualitative study by conducting personal interviews with healthcare professionals, which can enrich more deeper insight and more in-depth content.

\subsection{Implication and Recommendation}

This study is vital for healthcare settings to assess the impact of using the HER system in Qatar positively. The research hypothesis (H1) has been accepted after analyzing the results of the means, and it has positively influenced the study. The study will be helpful in identifying the influence of using the EHR system in Qatar. Further studies are recommended to be conducted in governmental healthcare settings in Qatar with a larger sample.

\subsection{Final Conclusion}

This study utilized an online survey tool that assesses the research hypothesis and answers the research question. The purpose of this study to assess the influence of using the EHR system in Qatar and how it perceived by healthcare professionals in terms of benefits, barriers, and motivations. Also, the study contributes to analyze and identify the level of IT training effect from the perspective of end-users (healthcare professionals).

\section{References}

Akhu-Zaheya, L., Al-Maaitah, R., \& Bany Hani, S. (2018). Quality of nursing documentation: Paper-based health records versus electronic-based health records. Journal of clinical nursing, 27(3-4), e578-e589.

Alasmary, M., El Metwally, A., \& Househ, M. (2014). The association between computer literacy and training on clinical productivity and user satisfaction in using the electronic medical record in Saudi Arabia. Journal of Medical Systems, 38(8), 69.

Al-Harbi, A. (2011). Healthcare providers' perceptions towards health information applications at King Abdul-Aziz Medical City, Saudi Arabia. International Journal of Advanced Computer Science and Applications, 2(10), 10-13.

Alharthi, H., Youssef, A., Radwan, S., Al-Muallim, S., \& Zainab, A. T. (2014). Physician satisfaction with electronic medical records in a major Saudi Government hospital. Journal of Taibah University Medical Sciences, 9(3), 213-218.

Andrus, M. R. (2012). Student pharmacist initiated medication reconciliation in the outpatient setting. Pharmacy practice, $10(2), 78$.

Anderegg, S. V., \& Gumpper, K. F. (2012). What meaningful use means for pharmacy. American Journal of Health-System Pharmacy, 69(10), 890-894.

Ayres, E. J., \& Hoggle, L. B. (2012). Advancing practice: using nutrition information and technology to improve health-the nutrition informatics global challenge. Nutrition \& Dietetics, 69(3), 195-197.

Bardach, S. H., Real, K., \& Bardach, D. R. (2017). Perspectives of healthcare practitioners: An exploration of interprofessional communication using electronic medical records. Journal of Interprofessional Care, 31(3), 300-306.

Carayon, P., Cartmill, R., Blosky, M. A., Brown, R., Hackenberg, M., Hoonakker, P., ... \& Walker, J. M. (2011). ICU nurses' acceptance of electronic health records. Journal of the American Medical Informatics Association, 18(6), 812-819.

Castillo, V. H., Martínez-García, A. I., Soriano-Equigua, L., Maciel-Mendoza, F. M., Álvarez-Flores, J. L., \& Juárez-Ramírez, R. (2019). An interaction framework for supporting the adoption of EHRS by physicians. Universal Access in the Information Society, 18(2), 399-412.

Celikkan, U., Sahin, Y. G., \& Senuzun, F. (2013). Perceived usefulness of data entry tools in medical encounters: a survey. Journal of Medical Systems, 37(6), 9988.

Chalmers, J., Siska, M., Le, T., \& Knoer, S. (2018). Pharmacy informatics in multihospital health systems: Opportunities and challenges. The Bulletin of the American Society of Hospital Pharmacists, 75(7), 457-464.

Chao, W. C., Hu, H., Ung, C. O. L., \& Cai, Y. (2013). Benefits and challenges of electronic health record system on stakeholders: A qualitative study of outpatient physicians. Journal of Medical Systems, 37(4), 9960.

Cole, A. M., B. Pflugeisen, M. R. Schwartz \& S. C. Miller. (2018). Cross sectional study to assess the accuracy of electronic health record data to identify patients in need of lung cancer screening. BMC Research Notes, 11, 1-4.

Culler, S. D., Jose, J., Kohler, S., \& Rask, K. (2011). Nurses' perceptions and experiences with the implementation of a medication administration system. CIN: Computers, Informatics, Nursing, 29(5), 280-288.

Cyganek, B., M. Graña, B. Krawczyk, A. Kasprzak, P. Porwik, K. Walkowiak \& M. Woźniak. (2016). A Survey of Big Data Issues in Electronic Health Record Analysis. Applied Artificial Intelligence, 30, 497-520.

de Hoon, S. E. M., K. Hek, L. van Dijk \& R. A. Verheij. (2017). Adverse events recording in electronic health record systems in primary care. BMC Medical Informatics \& Decision Making, 17, 1-6.

Deokar, A. V., \& Sarnikar, S. (2016). Understanding process change management in electronic health record implementations. Information Systems and e-Business Management, 14(4), 733-766.

Dowding, D. W., M. Turley \& T. Garrido. (2015). Nurses' use of an integrated electronic health record: results of a case site analysis. Informatics for Health \& Social Care, 40, 345-361. 
El Mahalli, A. A. (2015). Electronic health records: Use and barriers among physicianss in eastern province of Saudi Arabia. Saudi Journal for Health Sciences, 4, 32-41.

Emmendorfer, T., Glassman, P. A., Moore, V., Leadholm, T. C., Good, C. B., \& Cunningham, F. (2012). Monitoring adverse drug reactions across a nationwide health care system using information technology. American Journal of Health-System Pharmacy, 69(4), 321-328.

Hawley, G., J. Hepworth, C. Jackson \& S. A. Wilkinson. (2017). Integrated care among healthcare providers in shared maternity care: what is the role of paper and electronic health records? Australian Journal of Primary Health, 23, 397-406.

Holanda, A. A., e Sá, H. L. D. C., Vieira, A. P. G. F., \& Catrib, A. M. F. (2012). Use and satisfaction with electronic health record by primary care physicians in a health district in Brazil. Journal of Medical Systems, 36(5), 3141-3149.

Horning, R. (2011). Implementing an electronic medical record with computerized prescriber order entry at a critical access hospital. American Journal of Health-System Pharmacy, 68(23), 2288-2292.

Houser, S. H., \& Johnson, L. A. (2008). Perceptions regarding electronic health record implementation among health information management professionals in Alabama: a statewide survey and analysis. Perspectives in Health Information Management/AHIMA, American Health Information Management Association, 5.

Jabali, A. K. (2017). Progress in adopting EHR in Saudi eastern region private hospitals. International Journal of Healthcare Management, 10, 13-18.

Jawhari, B., Ludwick, D., Keenan, L., Zakus, D., \& Hayward, R. (2016). Benefits and challenges of EMR implementations in low resource settings: a state-of-the-art review. BMC Medical Informatics and Decision Making, $16(1), 116$.

Johnson, T. J., \& Brownlee, M. J. (2018). Development and innovation of system resources to optimize patient care. The Bulletin of the American Society of Hospital Pharmacists, 75(7), 465-472.

Kossman, S. P., \& Scheidenhelm, S. L. (2008). Nurses' perceptions of the impact of electronic health records on work and patient outcomes. CIN: Computers, Informatics, Nursing, 26(2), 69-77.

Kruse, G. R., H. Hays, E. J. Orav, M. Palan \& T. D. Sequist. (2017). Meaningful Use of the Indian Health Service Electronic Health Record. Health Services Research, 52, 1349.

Likourezos, A., Chalfin, D., Murphy, D., Sommer, B., Darcy, K., \& Davidson, S. (2004). Physician and nurse satisfaction with an electronic medical record system. Computers in Emergency Medicine, 27(4), 419-424.

Lövestam, E., Orrevall, Y., Koochek, A., Karlström, B., \& Andersson, A. (2015). Evaluation of N utrition C are P rocess documentation in electronic patient records: need of improvement. Nutrition \& Dietetics, 72(1), 74-80.

Makam, A. N., Lanham, H. J., Batchelor, K., Moran, B., Howell-Stampley, T., Kirk, L., ... \& Halm, E. A. (2014). The good, the bad and the early adopters: providers' attitudes about a common, commercial EHR. Journal of Evaluation in Clinical Practice, 20(1), 36-42.

Maunder, K., Walton, K., Williams, P., Ferguson, M., Beck, E., Ayres, E., \& Hoggle, L. (2015). Uptake of nutrition informatics in A ustralia compared with the USA. Nutrition \& dietetics, 72(3), 291-298.records: Need of improvement. Nutrition \& dietetics, 72(1), 74-80.

Mehmood, H., M. Aslam, S. Aslam, A. Waqar, A. Khan, Y. Hassan, F. M. Cheema, H. Mujtaba \& M. Noor e. (2017). ELECTRONIC HEALTH RECORD SYSTEMS; PERCEPTION AND EVALUATION AMONG PHYSICIANSS IN PAKISTAN. Professional Medical Journal, 24, 182-187.

Mosher, H. J., Lose, D. T., Leslie, R., Pennathur, P., \& Kaboli, P. J. (2015). Aligning complex processes and electronic health record templates: a quality improvement intervention on inpatient interdisciplinary rounds. BMC Health Services Research, 15(1), 1-9.

Ngafeeson, M. N. (2015). Healthcare information systems opportunities and challenges. In Encyclopedia of Information Science and Technology, Third

O'Mahony, D., Wright, G., Yogeswaran, P., \& Govere, F. (2014). Knowledge and attitudes of nurses in community health centres about electronic medical records. Curationis, 37(1), 01-06.Edition (pp. 3387-3395). IGI Global.

O'SULLIVAN, T. A., Billing, N. A., \& Stokes, D. (2011). Just what the doctor ordered: Moving forward with electronic health records. Nutrition \& Dietetics, 68(3), 179-184.

Pedersen, C. A., Schneider, P. J., \& Scheckelhoff, D. J. (2016). ASHP national survey of pharmacy practice in hospital settings: monitoring and patient education-2015. American J ournal of Health-System Pharmacy, 73(17), $1307-1330$.

Penoyer, D. A., Cortelyou-Ward, K. H., Noblin, A. M., Bullard, T., Talbert, S., Wilson, J., ... \& Briscoe, J. G. (2014). Use of electronic health record documentation by healthcare workers in an acute care hospital system. Journal of healthcare management, 59(2), 130-144.

Petrides, A. K., I. Bixho, E. M. Goonan, D. W. Bates, S. Shaykevich, S. R. Lipsitz, A. B. Landman, M. J. Tanasijevic \& S. E. F. Melanson. (2017). ze The Benefits and Challenges of an Interfaced Electronic Health Record and Laboratory Information System Effects on Laboratory Processes. 410-417.

Probst, Y. (2011). Dietitians in the electronic age: Progressing towards e-health. Nutrition \& Dietetics, 68(3), 177-178. doi: 10.1111/j.1747-0080.2011.01542.x

Rind, D. M., Safran, C., Phillips, R. S., Wang, Q., Calkins, D. R., Delbanco, T. L., ... Slack, W. V. (1994). Effect of computerbased alerts on the treatment and outcomes of hospitalized patients. Archives of Internal Medicine, 154(13), $1511-1517$. Doi:10.1001/archinte.1994.0042013010714

Sakata, K. K., Stephenson, L. S., Mulanax, A., Bierman, J., Mcgrath, K., Scholl, G., ... \& Gold, J. A. (2016). Professional and interprofessional differences in electronic health records use and recognition of safety issues in critically ill patients. Journal of Interprofessional Care, 30(5), 636-642. 
Shachak, A., \& Reis, S. (2009). The impact of electronic medical records on patient-doctor communication during consultation: a narrative literature review. Journal of Evaluation in Clinical Practice, 15(4), 641-649.

Schenk, E., Schleyer, R., Jones, C. R., Fincham, S., Daratha, K. B., \& Monsen, K. A. (2018). Impact of adoption of a comprehensive electronic health record on nursing work and caring efficacy. CIN: Computers, Informatics, Nursing, 36(7), 331-339.

Shahmoradi, L., A. Darrudi, G. Arji \& A. F. Nejad. (2017). Electronic Health Record Implementation: A SWOT Analysis. Acta Medica Iranica, 55, 642-649.

Shield, R. R., Goldman, R. E., Anthony, D. A., Wang, N., Doyle, R. J., \& Borkan, J. (2010). Gradual electronic health record implementation: new insights on physician and patient adaptation. The Annals of Family Medicine, 8(4), 316-326.

Singer, A., \& Fernandez, R. D. (2015). The effect of electronic medical record system use on communication between pharmacists and prescribers. BMC Family Practice, 16(1), 155.

Singh, B., \& Muthuswamy, P. (2013). Factors affecting the adoption of electronic health records by nurses. World Applied Sciences Journal, 28(11), 1531-1535.

Steinhubl, S. R., \& Topol, E. J. (2015). Moving from digitalization to digitization in cardiovascular care: why is it important, and what could it mean for patients and providers?. Journal of the American College of Cardiology, 66(13), 1489-1496.

Strudwick, G. \& L. McGillis Hall. (2015). Nurse acceptance of electronic health record technology: a literature review. Journal of Research in Nursing, 20, 596.

Taylor, S. P., Ledford, R., Palmer, V., \& Abel, E. (2014). We need to talk: an observational study of the impact of electronic medical record implementation on hospital communication. BMJ Quality Safety, 23(7), 584-588.

U.S. Department of Health and Human Services, (2009), Health information technology. Retrieved July 22, 2009, from http://healthit.hhs.gov/portal/server.pt?open=512\&objID=1204\&parentname=CommunityPage\&parentid=2\&mode $=2 \&$ in hi userid $=10741 \&$ cachached $=$ true.

Ventres, W., Kooienga, S., Vuckovic, N., Marlin, R., Nygren, P., \& Stewart, V. (2006). Physicians, patients, and the electronic health record: an ethnographic analysis. The Annals of Family Medicine, 4(2), 124-131.

Vitari, C. \& R. Ologeanu-Taddei. (2018). The intention to use an electronic health record and its antecedents among three different categories of clinical staff. BMC Health Services Research, 18, 1-1.

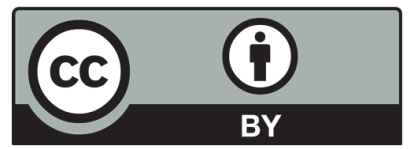

(C) 2021 by the authors; licensee Growing Science, Canada. This is an open access article distributed under the terms and conditions of the Creative Commons Attribution (CC-BY) license (http://creativecommons.org/licenses/by/4.0/). 